\title{
Functionality of Service-oriented Institutions Vis-à-vis Rural Development Situation in Eastern Samar, Philippines
}

\author{
Dr. Hilarion A. Odivilas \\ Director, Research and Development, \\ Eastern Samar State University, Borongan, Eastern Samar, Philippines
}

doi: 10.19044/esj.2016.v12n17p50 URL:http://dx.doi.org/10.19044/esj.2016.v12n17p50

Abstract

This study ascertained the functionality of service-oriented institutions in relation to rural development situation in Eastern Samar. It aimed to: (a) determine the perceptions of the rural poor on the functionality of identified institutions in terms of their assistance extended and the type of benefits derived, (b) analyze the development situation of the municipalities of Eastern Samar in terms of socio-economic status, health conditions, education and training and peace situation, and (c) evaluate the relationship between the perceived functionality of the institutions and the development situation of Eastern Samar. The study utilized the descriptive-correlational design, with the use of an interview guide, in order to determine the functionality of the identified institutions and the development situation of the different municipalities of the province using Mean and Pearson Productmoment Coefficient Correlation. Government organizations, nongovernment organizations, community organizations and local government units had functional performance in development projects. However, the assistance extended by different agencies perceived to be highest did not consistently provide the highest benefits. These brought about by the organizations' resource capabilities, extent of implementation and the choice of the beneficiaries. The similarity of community needs and resources and the scope of the organizations' objectives influenced the similarity of activities in the barangays. Other NGOs, community organizations and local government units performed similarly in all barangays. Majority of the respondents had low income and lived in wooden type of houses, had fair health conditions, finished elementary education enough to have the ability to read and write. A greater majority of the respondents' children of school age were in school. With peaceful communities in Eastern Samar, low criminality rate and low presence of communist-oriented elements 
contributed to the development assistance extended by the LGUs in terms of education and livelihood projects.

Keywords: Service-oriented institutions, development situation, extended assistance

\section{Introduction}

The world today experiences a rapid and continuous change. In some cases, these changes are favorable; at other times, these are unfavorable, more especially in the Philippines where its often visited by more than 20 typhoons annually, and the province of Borongan in Eastern Samar is seldom spared, more or less, from these catastrophes. Some countries are rapidly progressing; others lag lackadaisically behind. As Todaro (1983) observes, different countries in the world have different levels of development. There is a common observation, however, those countries that have been poor and remained stagnant for centuries are striving to, at least, minimize if not to completely eradicate poverty, disease, ignorance and inequality. There is a worldwide aspiration for development that is more than just the desire for economic progress. It is a quest for status, prestige, recognition, and for social and economic modernization. Contrary to these aspirations, the reality of underdevelopment has tremendously affected the social order of the community. Gaulit (1971) in Todaro (1983) says:

"Underdevelopment is shocking: the squalor, the disease, unnecessary deaths, and hopelessness of it all. No man understands if development remains for him a mere statistics reflecting lower income, poor housing, premature mortality, or underdevelopment. The most emphatic observer can speak objectively about underdevelopment only after undergoing personally the 'shock of underdevelopment'. This unique culture shock comes to one as he or she is initiated to the emotions which prevail in the 'culture of poverty'. The reverse shock is felt by those living in destitution when a new self-understanding reveals to them that their life is either human or inevitable".

Development is more than a passage from poor to rich, from traditional rural economy to a sophisticated urban business (Casley and Lurey, 1981). It carries with it not only the idea of economic betterment; but also a greater human dignity, security, justice and equity. The implementation of the right to development implies the participation of those concerned in the formulation and application of development policies based on the principle of self-reliance and respect for human rights. Citing the 
views of Coombs and Ahmed of the World Bank, Fitzsimons and Freedman (1987) stressed that rural development should be:

"...not simply... agricultural and economic growth in the narrow sense; but... balanced social and economic development, with emphasis on equitable distribution as well as the creation of benefits. Among the goals are the generation of new employment, the more equitable access to arable lands, more equitable distribution of income, widespread improvements in health, nutrition and housing; greatly broadened opportunities for all individuals to realize their full potential through education; and a strong voice for all rural people in shaping the decisions and action that affect their lives."

Historically, the advent of the New Society in the Philippines in the early 70s gives an increased attention to rural development. As reflected in the Philippine Development Plan, the underlying philosophy of development underscores by no less than the late President Ferdinand E. Marcos who laments that:

"In the New Society, development does not only imply economic advancement. It also means improvement in the well-being of the broad masses of our people. It means getting down and reaching the poor segments of our population, the urban and rural poor, the unemployed, the homeless dweller, the out-of school youth, the landless worker, the sacada (sugarcane peasants), and the sustenance fisherman (Cuyno, 1985).”

Community development is a way of strengthening civil society by prioritizing the actions of their communities, and their perspectives in the development of social, economic and environmental policy. It seeks the empowerment of local communities and takes both geographical communities of interest or identity and communities organizing around specific themes or policy initiatives, as a vibrant element. It strengthens the capacity of people as active citizens through their community groups, organizations and networks; and the capacity of institutions and agencies (public, private and non-governmental) to work in dialogues with citizens to shape and determine change in their communities (Scottish Community Development Center, 2015).

Community development is about community building as such, where the process is as important as the results. One of the primary challenges of community development is to balance the need for long-term solutions with the day-to-day realities that require immediate decisionmaking and short-term action (Frank and Smith, 2015). National government 
agencies, like Department of Agriculture (DA), the Department of Education (DepEd), the Department of Agrarian Reform (DAR), to mention some, identify some program policies that enhance the attainment of the development goals in addition to their respective major functions. Likewise, the local government units (either in the municipal or barangay level) which are the frontline in the implementation of the different programs and projects of these aforementioned line agencies also have their own rural development thrusts that are designed to satisfy the needs of their respective constituents.

\section{Review of Literature}

Development is a sociological perspective that involves primarily social change. Philips (1970) in Garcia (1985) emphasizes that social change converges around the idea of development. For development to take place in a society, all its structures-social, economic and political-should serve as stimulants to change. If they pose as barrier, development becomes unattainable. Hence, development seems to be much closely related to social change.

To the layman, development means having adequate food, i.e. the opportunity to eat three times a day; adequate education to have been able to send children in school; enough income to meet the basic needs like clothing, housing, food and medicines, in order to maintain a healthy quality of life. In other words, Chamber (1994) views "Rural Development (RD) as a strategy to enable a specific group of people like: poor rural women and men gain for themselves and their children more on what they want and need.” It involves helping the poorest among those who seek a livelihood in the rural areas to demand and control more of the benefits of rural development. The group includes small scale farmers, tenants, and the landless.

In order to see the essence of rural development, agriculture as a backbone of the economy becomes a vibrant sector for development. "Agriculture is regarded as the primary means to generate income for the poor and secure access to food both in the rural and in urban areas" (Gadzama, 2013). This means that intensification of farm development necessitates the influence of urban development through the expansion of roads for the transportation of goods from the farm to the market, providing enough budget allocation to farmers more especially on the use of organic fertilizers and insecticides in order to increase yields of production.

One way to mitigate poverty situation in the rural communities is the intensification of farming methods to yield better harvests and provide food on the table. Carbonell (2015) emphasizes the use of long-term productivity, farm diversification and economic profitability where farmers are motivated to use alternative farming ways like organic farming, in order to maintain sustainable agriculture and ensure a better quality of human life. 
Another way to maintain the soil condition and adapt an environmentally friendly attitude is the use of mulching process of organic materials like leaves of plants on the ground where crops grow like bananas among others to limit the growth of wedges that affects the stunted growth of plants. Mulching is a process of overlaying materials usually organic residues on the ground surface in order to conserve moisture, control weed growth, and provide organic matter to the plant (Nierrras, 2015).

To Bautista (1994), asserts the need for agricultural development in different parts of the Philippines to be more self-sustaining and equitable. This assertion is a response to find a solution of the bourgeoning situation of massive poverty in the Philippines. He further says that since 1965-80, the Philippine government has an impressive growth in agriculture, fueled by rapid increase in farm productivity. But, as the succeeding 20 years since the eighties, the country has faced a lot of challenges. The threat for natural disasters like typhoons destroys most of the farm crops and consequently affects the standard of living among the farmers and the fisher folks. This scenario has been aggravated by issues of corruption in government which budget for agriculture modernization has been diverted to other government priorities or worst it goes to the pockets of other politicians and their allies.

In the Philippines, one of the early post-war experiments in rural development is undertaken by the Philippine Rural Reconstruction Movement (PRRM) in 1952. Under the leadership of Dr. V.C. James Yen, the program revolves around the four-fold goal in promoting livelihood education, public health and self-government for the rural populace. It utilizes multi-purpose rural reconstruction workers who live and work with villagers (Cuyno, et. al. 1982). Rural development is a desired state for people residing in rural areas. It is characterized by increased agricultural productivity and income, good governance, improved people empowerment, good health and nutrition, to have dignity and honor in living in a sustainable environment and a free society (Battad, 2003).

\section{Objectives of the Study}

This study ascertained the functionality of service-oriented institutions in relation to rural development situation in Eastern Samar. It aimed to: (a) determine the perceptions of the rural poor on the functionality of identified institutions in terms of their assistance extended and the type of benefits derived, (b) analyze the development situation of the municipalities of Eastern Samar in terms of socio-economic status, health conditions, education and training and peace situation, and (c) evaluate the relationship between the perceived functionality of the institutions and the development situation of Eastern Samar. 


\section{Methods and Materials}

The study utilized the descriptive-correlational design, with the use of an interview guide, in order to determine the functionality of the identified institutions and the development situation of the different municipalities of the province. The data are treated with the use of Mean and Pearson Productmoment Coefficient Correlation.

\section{Results and Discussion}

\section{A. Functionality of Service-oriented Institutions}

The Department of Trade and Industry (DTI) is perceived to have the most number of assistance in the area of cooperatives $(M=4.80)$, the Department of Education (DepEd) in education area $(\mathrm{M}=4.03)$, the Department of Agriculture (DA) in agriculture programs (M=4.00), Department of Health $(\mathrm{DOH})$ in health related projects $(\mathrm{M}=4.00)$, Department of Science and Technology (DOST) in livelihood projects $(\mathrm{M}=3.08)$, Department of Environment and Natural Resources (DENR) in physical areas $(\mathrm{M}=4.00)$, Department of Social Welfare and Development (DSWD) in social/livelihood related projects $(M=4.00)$ and Department of Public Works and Highways (DPWH) on physical related areas (M=4.00). These indicate that respondents have strong confidence about the different agencies of the national government. This is attributed by good governance of people in government. For instance, the program of the Aquino administration for "Sa Daang Matuwid" (On the Straight Road), a drive for wiping out corruption in government, affects the confidence of the Filipinos to work very hard to support the republic.

On the other side, the non-government organizations are perceived to have extended assistance as follows: The Union Citizen's Organization lead the extension of assistance in terms of cooperative projects ( $M=4.00)$ and in health and sanitation ( $M=3.33)$, Community Credit Cooperative $(M=3.67)$, Multi-purpose Credit Cooperative in livelihood projects $(M=3.25)$, and People Development Federation in the areas of health and sanitation $(\mathrm{M}=3.00)$. The community organizations likewise supported the communities in various areas. Samahang Magsasaka (farmers group) leads in the areas of cooperatives $(\mathrm{M}=4.50)$ and in physical and cultural development $(\mathrm{M}=4.00)$. Barangay Irrigators Association, in livelihood $(\mathrm{M}=3.71)$ and in cooperative projects $(\mathrm{M}=4.00)$. Small Fishermen Association has extended most in the area of health and sanitation $(M=3.67)$. The functionality of assistance by the local government units leads by the Barangay Development council in areas of cooperatives $(M=4.50)$, as the highest, health and sanitation $(\mathrm{M}=3.84)$, while the Municipal Government Council follows in the areas of health and sanitation $(M=3.75)$. The roles of different NGOs of the country are vital to support the inadequate services of 
the government organizations. This means that these organizations serve as a co-equal to provide the necessities of the most neglected members of the Filipino populace, more especially during the times of calamities.

\section{B. Functionality in terms of benefits}

The government organizations have been pioneered by the DTI in terms of cooperatives $(\mathrm{M}=4.50)$, DepEd in health and sanitation $(\mathrm{M}=3.96)$ and in physical and cultural development (M=4.08), DA in livelihood and in cooperatives (3.82), DOH in health and sanitation $(M=4.00)$, DOST in Physical development ( $\mathrm{M}=3.67)$, DENR in physical development, DSWD in health and sanitation (M=3.97) and DPWH in physical development $(\mathrm{M}=4.00)$ Among the non-government organizations, the highest benefits afforded are in areas of cooperatives. These are provided by the Union Citizen Association ( $M=4.10)$, Multi-purpose Credit Cooperative ( $M=3.75)$, People's Development Federation (M=3.67), and Community Credit Cooperative ( $M=3.67)$. Community organization has provided its share of benefits to the people as follows: Samahang Magsasaka in cooperative projects $(M=4.50)$, and livelihood assistance $(M=3.65)$, Small Coconut Framers Association in physical development $(M=4.00)$, Barangay Irrigators Association, in cooperatives $(\mathrm{M}=4.00)$ and Small Fishermen Association in livelihood ( $\mathrm{M}=3.67)$. Finally, the local government units extend the benefits to the people through Barangay Development Council in areas of cooperative $(M=4.50)$ and health and sanitation $(M=3.86)$, while the Municipal Government Council contributes benefits in the areas of health and sanitation $(\mathrm{M}=3.80)$. The aforementioned findings indicate that government agencies provide benefits not only based on their generic functions but also in the part of forming cooperatives and organized members, more especially women, to join business in microfinance in order to be sustainable. Desoloc (2104) rejoins that in Northern Quezon, women are involved in environmental projects, community development, and gender and development projects. Abocejo, Pañares, Dotillos, Diones, Belciña (2012) rejoin that women empowerment was evident with strong participation of wives in microfinance projects, in rural development.

\section{Development Situation of the Municipalities in Eastern Samar}

In terms of Socio-Economic Status, $51.7 \%$ of the respondents have an income of P250.00 and below per week while 43.5\% of the respondents are living in category $C$ type of houses. As to health and sanitation, the respondents reach a Mcomb. of 4.85 or fair health condition, while on education aspect, the respondents perceived themselves to be moderately educated (Mcomb.=5.23). Further, in terms of the participation of their children in school, $76.9 \%$ claims that they have their children of school age 
while $22.9 \%$ are identified to have no children in the same category. For peace and order situation, $79.6 \%$ of the subjects have responded that there is no criminality incidence in their respective communities. While, $83.3 \%$ of them claim that they have not experienced the presence of communistoriented elements in their barangays. These data indicate that the municipalities of Eastern Samar are relatively peaceful, which affects greatly their socio-economic status as farmers and fishermen in the region.

\section{Relationship between the development assistance extended and development situation in Eastern Samar}

In terms of relationship between developments assistance extended by government organizations and development situation, it is shown that there is no association between the extent of assistance extended and development situation of the municipalities. This may be viewed that the development assistance provided has no direct impact on their lives. This failure may be traced to the selection of immediate beneficiaries where most of the service programs do not reach the lowest level of the poor. These are construed that while some local government officials manage to appropriately distribute the meager government budget to the different stakeholders of the community. Few others officials are also diverting these funds to corruption for their self-vested interest at the expense of the poor. The present Aquino administration has mitigated this practiced by introducing the Conditional Cash Transfer or CCT Program known as the 4Ps, Pantawid Pamilyang Pilipino Program, through the efforts of the Department of Social Welfare and Development in different regions of the country. The 4Ps alleviates the level of poverty in the countryside (Ranario, 2012).

Table 1 Relationship between the Development Assistance extended by Government Organizations and the Development Situation

\begin{tabular}{|c|c|c|c|}
\hline Development Situation & $\mathrm{R}$ & Probably Level & Interpretation \\
\hline Livelihood & .06 & $>.30$ & Not Significant \\
Education & .04 & $>.35$ & Not Significant \\
Health and Sanitation & -.006 & $>.22$ & Not Significant \\
Physical/Cultural & & & \\
Cooperatives & .085 & $>-.22$ & Not Significant \\
& -.458 & $>.13$ & Not Significant \\
\hline
\end{tabular}

In terms of relationship between the development assistance extended by non-government organizations and the development situation, Table 2 does not show any significant correlation. This is attributed by the novelty of assistance extended to the communities. Its impact is not felt by the respondents, which may possibly due to the projects', technological options, design and nature of implementation of the agencies. This is viewed by 
looking into the attitudes and culture of the people in Eastern Samar. While they are industrious, hardworking and sturdy, they feel they do not readily adopt new practices. The conventional farming/fishing practices which have served them well are retained among many options for survival. When it comes to the changes, therefore, they adopt a "wait and see" attitude before they venture a new project or change in their lives (Situation of Children and Women in the Province of Eastern Samar, UNICEF, 1993). This means that attitudes of people in different cultures cannot be easily swayed when new changes are introduced.

Table 2 Relationship between the Development Assistance extended by Non-Government Organizations and the Development Situation

\begin{tabular}{|c|c|c|c|}
\hline Development Situation & $\mathrm{r}$ & Probably Level & Interpretation \\
\hline Livelihood & .06 & $>.37$ & Not Significant \\
Education & .02 & $>.74$ & Not Significant \\
Health and Sanitation & .19 & $>.21$ & Not Significant \\
Physical/Cultural & -.20 & $>-.60$ & Not Significant \\
Cooperatives & .24 & $>.39$ & Not Significant \\
\hline
\end{tabular}

The relationship between the development assistance extended by community organizations and the development situation shows no direct contribution to existing community development situation. The nonsignificant relationship is attributed to the failure of community organizations to penetrate to all sectors of the community; thereby causing lesser impact of development as this assistance is confined to limited areas. This shows the relative incompetence of some community organizers when comes to ensuring the total package of community development that address peculiar issues on poverty, malnutrition, domestic violence, and gender inequality which are rooted in rural farming communities. Vis-à-vis, Gadzama (2013) asserts that these issues are to be responded in order to protect the community security, which he defines as "as a means that people gain security from their membership of a social group whether it is a family, a community, an organization or an ethnic group".

Table 3 Relationship between the Development Assistance extended by Community Organizations and the Development Situation

\begin{tabular}{|c|c|c|c|}
\hline Development Situation & $\mathrm{r}$ & Probably Level & Interpretation \\
\hline Livelihood & .06 & $>.05$ & Not Significant \\
Education & -.15 & $>.05$ & Not Significant \\
Health and Sanitation & .26 & $>.05$ & Not Significant \\
Physical/Cultural & -.27 & $>.05$ & Not Significant \\
Cooperatives & -.48 & $>.05$ & Not Significant \\
\hline
\end{tabular}

With regard to the relationship between the development assistance extended by local government units and the development situation, it is worthy to mention that "livelihood projects" and "education" both prove to be significantly related. The former yields and $\mathrm{r}$ of $-.20(\mathrm{p}=<.03)$ and the 
latter, an $\mathrm{r}$ of $.16(\mathrm{p}=<.05)$. These results indicate significant association between the two sets of paired variables. These results have occurred considering that education assistance is perceived to have contributed to the development situation of the residents, being seen as a collaborative endeavor of the parents, teachers, and support of the barangay development council. The same is true with livelihood projects, where major assistance is extended by the LGUs; thus, creating a major vehicle on their livelihood improvement. This means that education is a great equalizer to development. If we want people to be sustainable, government prioritizes budgetary allocation for education. This is one of the main goals of the New K to 12 Program implementation in the Philippines under Republic Act 10533 (Inocian, 2015).

Table 4 Relationship between the Development Assistance extended by Local Government Units and the Development Situation

\begin{tabular}{|c|c|c|c|}
\hline Development Situation & $\mathrm{r}$ & Probably Level & Interpretation \\
\hline Livelihood & -.20 & $<.03$ & Significant \\
Education & .16 & $<.05$ & Significant \\
Health and Sanitation & .05 & $>.31$ & Not Significant \\
Physical/Cultural & -.14 & $>.29$ & Not Significant \\
Cooperatives & .05 & $>.92$ & Not Significant \\
\hline
\end{tabular}

'Hunger has threatened the lives of many people in developing countries' (Gadzama, 2013). This relates the assistance extended by the local government units to the development situation in Eastern Samar where livelihood and education are shown significant. This means that the immediate response by the community members is survival more than anything else. In livelihood, they can earn money in order to buy the basic necessities for survival. In the outset, they recognized the need to be educated in order for them to learn basic literary and numeracy not to be deceived about the use of resources and the proper use of the value of spending money. Health and sanitation, physical/cultural, and participation in cooperatives remain insignificant because these are already existent in the life of the entire rural community.

\section{Conclusion}

All government organizations, non-government organizations, community organizations and local government units had functional performance in one or more of the development assistance and were able to implement development projects. However, the assistance extended by different agencies perceived to be highest did not consistently provide the highest benefits. These brought about by the organizations' resource capabilities, extent of implementation and the choice of the beneficiaries. All community organizations extended similar activities in all barangays. The 
similarity of community needs and resources and the scope of the organizations' objectives influenced the similarity of activities in the barangays. All other NGOs, community organizations and local government units performed similarly in all barangays. Majority of the respondents had low income and lived in wooden type of houses, had fair health conditions, finished elementary education enough to have the ability to read and write. A greater majority of the respondents' children of school age were in school. With peaceful communities, in Eastern Samar, low criminality rate and low presence of communist-oriented elements contributed to the development assistance extended by the local government units in terms of education and livelihood projects.

\section{Recommendations}

In order to improve the functionality of the service programs of government agencies, non-government organizations, community organizations and local government units the following need to be done: (1) responsible persons identify the present areas of conflict between different policies and projects among service-oriented institutions, (2) plan out and implement strong collaborative policies and guidelines for the various organizations involved by considering individual institutions resource capabilities thereby instituting a particular focus of interest on the service programs for rural development, (3) as regards to the improvement of the present development situation of Eastern Samar, the following should be considered: there is a need for a thorough analysis of target groups and the constraints inherent in the linkage between access and use of resources, projects should be designed with sufficient attention to the impact on the distribution of income and benefits, and a thorough evaluation on the effects of projects interventions of target groups be made as one of the basis for implementing future rural development programs. Finally, policy makers and stakeholders to further evaluate the findings of the study as inputs in formulating rural development programs in the province and in other areas in the Philippines with similar living situations of Eastern Samar.

\section{References:}

Abocejo, F. et. al. (2012). Microfinance lending program of cooperatives in cebu, Philippines: realities, benefits and women's participation. Cebu Normal University Journals of Higher Education, Special Issue on Poverty Alleviation, Cebu City, Philippines

Bautista, R. (1994). Dynamics of rural development: analytical and policy issues. Journal of Philippine Development, Vol. XXI, No. 38.

Casley, D. and Lurey (1981). Data collection on developing countries. Oxford: Clareden Press. 
Carbonell, S. (2015). Correlates of queen pineapple (Ananascomosus Linn) farming practices in Camarines Norte, Philippines. Asia Pacific Journal of Multidisciplinary Research, Volume 3, No. 5.

Cuyno, R. et. al (1985). Management of rural development: philippines reflections. Quezon City. UP Press.

Desoloc, MS (2014). Women empowerment and climate change adaptation in northern quezon. Asia Pacific Journal of Multidisciplinary Research. Volume 2, No. 5.

Fitzsimmons, S. and Freedman, A. (1987). Rural community development. Massachusetts: Abt Books.

Frank and Smith (2015). What is community development. Retrieved from http://www.peernet.com/what-is-community-development

Gadzama, IU (2013). Effects of president umaru musa yar' aduas' 7-point agenda on agricultural development and food security in Nigeria. European Scientific Journal. Volume 9, No. 32.

Inocian, R. (2015). Quadrant modelling in teaching (qmt): responding to RA 10533 salient provisions. Asia Pacific Journal of Education, Arts and Sciences, Vol. 2 No. 4

Nierras, M. (2015). Effect of basal density of mulched materials on the growth and fruiting performance of table banana (Latuntan var.). Asia Pacific Journal of Multidisciplinary Research, Volume 3, No. 5.

Ranario, R. (2012). The pantawid pamilya: a TEPA analysis of the Philippines poverty reduction strategy. Cebu Normal University Journals of Higher Education, Special Issue on Poverty Alleviation, Cebu City, Philippines

Scottish Community Development Center (2015). Retrieved from http://www.scdc.uk/who/what-is-development/

Todaro, M, (1983). Economic development on the third world: $2^{\text {nd }}$ edition. New York: Longman.

(1993). Situation of children and women in the province of eastern samar. Provincial Government of Eastern Samar, UNICEF, NEDA 8 